\section{Genomics of grain quality in cereals}

\section{Robert J Henry ${ }^{1^{*}}$}

Abstract: Rapid advances in genomics are providing the tools to determine the genetic basis of quality (both nutritional and functional) in cereals. This promises to allow increased rates of genetic gain in breeding by reducing the need for extensive end-product testing of new varieties. Many quality traits are the result of relatively recent human selection and are thus likely to be controlled by only a few major genes. This makes identification of these genes for use in breeding selection an attractive target for breeders. Examples of the discovery of genes that are major contributors to key grain quality attributes include, fragrance and cooking temperature in rice (identified by re-sequencing) and loaf volume and milling yield in wheat (identified by transcriptome analysis). Extension of genomic tools to an analysis of the wider gene pool including wild relatives will enable the identification of alleles that may contribute to improved or novel grain quality in the future and may be critical to ensuring quality is retained in a changed climate. Completely new cereal species might be produced.

Keywords: Genomics, sequencing, wheat, rice, maize, barley, sorghum, enduse quality.

\section{IMPORTANCE OF GRAIN QUALITY}

Food security requires the availability of sufficient quantities of food with the nutritional attributes required to support health populations. Food must also be attractive and convenient to the consumer. Consumer choice of food is increasingly influenced by factors beyond price, taste and convenience. Perceptions of the health benefits, sustainability of production or social impact of food choice are important for many.

Cereals remain a very significant part of global diets either supporting humans directly in food or by feeding animals that are the more direct source of human food. Cereal genotypes need to perform well in environments that are changing and becoming more variable and support the production of foods that satisfy these complex consumer demands. Genomics provides tools that facilitate this difficult breeding challenge (Henry 2007).

This review presents the author's views on some achievements and the prospects for further advances in grain quality using genomics (Henry et al. 2018, Henry et al. 2016).

\section{GENOMES OF MAJOR CEREALS}

The genomes of the major cereal crops are complex but advances in DNA sequencing (Murigneux et al. 2020) have made good quality reference genomes available for all major species. High quality sequences are likely to be available
Crop Breeding and Applied Biotechnology 21(S): e379821S1, 2021 Brazilian Society of Plant Breeding. Printed in Brazil http://dx.doi.org/10.1590/198470332021v21Sa14

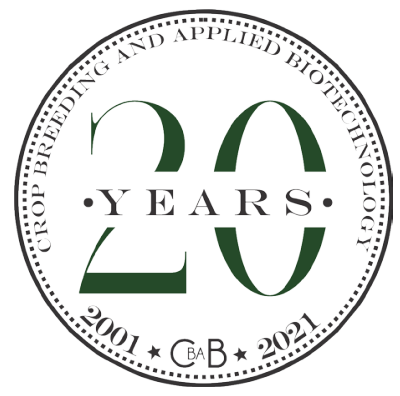

*Corresponding author: E-mail: robert.henry@uq.edu.au (iD) ORCID: 0000-0002-4060-0292

Received: 17 April 2021 Accepted: 29 April 2021 Published: 31 May 2021

\footnotetext{
${ }^{1}$ Queensland Alliance for Agriculture and Food Innovation, University of Queensland, Brisbane, Qld 4072, Australia
} 


\section{RJ Henry}

for even very minor cereal species in the near future. A high proportion of the genes have now been annotated to ascribe at least a general category of function. Genomics has begun to be applied to cereal quality improvement efforts.

The need for more than a single reference genome for each species has been apparent for some time and the pan genome concept is now being widely applied to cereal species. For example, early reference genomes for wheat have lacked many of the key genes and alleles for end use quality as they have been based upon genotypes without these traits. Extensive re-sequencing of germplasm will see the identification of most common alleles in the gene pools of major species (Henry 2012).

\section{GENOMIC BREEDING FOR QUALITY}

The future breeding task at the genomic level will be to design genotypes with the most desired allele of each gene for the target production environment and product specification. The delivery of this designed genotype may then be achieved by the processes of recombination by using the closest parental starting material to provide the background genotype and gene editing to modify many of the alleles to the desired final sequence. This will require an understanding of the functional significance of each allele. The application of this approach to cereal quality breeding may become feasible sooner that it will for agronomic performance because number of genes that require a high level of analysis and understanding may be far lower for quality traits that for yield traits. Grain yield maybe determined by a very large number of genes and complex networks of control and environmental response. These traits have evolved over a very long period of time. In contrast grain quality traits are the product of human selection in the relatively short period of 10,000 years since domestication began. As a result many traits unique to domesticate cereals are relatively simple and controlled by one or a few major genes that have been selected by humans. They may also be under more independent genetic control than other traits (Kumar et al. 2019). If we can use genomics to identify and characterize these genes selected by humans, we can develop very efficient genomic tools for breeding for grain quality.

\section{Advancing genomic strategies for discovery of the molecular and genetic basis of grain quality}

The identification of key genes determining grain quality traits can be achieved by conventional genetic mapping techniques but direct genomics approaches are especially valuable. For some traits re-sequencing the genome of genotypes that differ for the trait can allow association with the quality trait. High quality reference genomes can now be readily generated (Murigneux et al. 2020). Advances in sequencing technology now mean that re-sequencing can either target specific genes or chromosomal regions if the location of the gene is known or cost effectively resequence the whole genome if such knowledge is lacking. Analysis of differential expression between genotypes that differ for the traits is also a path to gene identification. RNA-seq analysis is now a well-established tool for analysis of differences in the transcriptome. Analysis developing and mature grains can reveal the genetic determinants of grain composition and as result grain quality (Ragan et al. 2017). This tool also allows the impact of environment on grain quality to be explored (Ragan et al. 2019, 2020). Examples of the use of genomics to link genes to quality traits are given in Table 1.

\section{Examples of genome sequencing revealing the molecular basis of grain quality}

Re-sequencing of the genomes of genotypes with differing quality can be used to determine the genetic basis of grain quality traits. The variations in the genomes of groups of genotypes with extremes of the traits can be used to define the key genes and sequence differences responsible for the trait (Wambugu et al. 2018).

Table 1. Examples of genetic basis of cereal quality revealed by genomic analysis

\begin{tabular}{lcccc}
\hline Species & Trait & Gene & Method & Reference \\
\hline Rice & fragrance & badh2 & re-sequencing & Bradbury et al. (2005) \\
Rice & cooking temperature & $s s / l a$ & re-sequencing & Waters et al. (2006) \\
Wheat & loaf volume & $w b m$ & RNA-seq & Furtado et al. (2015) \\
Wheat & milling yield & RNA-seq & Nirmal et al. (2017) \\
Wheat & hardness & pin genes & RNA-seq & Nirmal et al. (2016) \\
\hline
\end{tabular}


Rice Fragrance is a trait that can double the value of rice. The gene for fragrance in rice (Bradbury et al. 2005) was discovered by utilizing the rice genome sequence. Molecular markers had been used to map the location of the recessive gene controlling this trait (Jin et al. 2003). When the draft sequence of rice became available it was possible to identify the gene responsible in just a few weeks. Flanking marker were available that indicated the gene was in a $1 \mathrm{Mb}$ region. Re-sequencing and examination of each of the genes in this region quickly identified a gene, badh2, that had a deletion causing a frameshift in all the fragrant varieties but not the non-fragrant ones (Bradbury et al. 2005, Bradbury et al. 2008).

\section{Rice cooking temperature}

The cooking temperature of rice is the gelatinization temperature of the starchy endosperm (Waters et al. 2006). As the properties of the rice starch were known to be involved, starch biosynthesis genes were candidates for control of this trait. Re-sequencing of starch biosynthesis genes in many genotypes revealed that SNP that changed an amino acid in a key region of sslla resulted in a difference of $11{ }^{\circ} \mathrm{C}$ in the gelatinization temperature.

\section{Examples of transcriptome analysis revealing the molecular basis of grain quality}

The development of RNA Seq methods has allowed the routine quantitative comparison of the genes expressed in any specific tissue of at any stage of grain development. Analysis of the transcriptome of the developing grain (Ragan et al. 2017) is a key approach to discovery of the genetic basis of grain quality traits (Henry et al. 2018). This approach can complement other approaches such as re-sequencing to accelerate discovery of genes determining grain quality.

\section{Wheat loaf volume}

Wheat is widely used to produce bread. The ability of bread made from wheat to rise and the resulting high volume of the loaf is a key and unique tribute of wheat. Breeders select for high loaf volume in breeding high quality wheat genotypes. This needs to be done by making small loaves of bread and assessing their size. This is a major constraint on breeding as it requires large amounts of flour only available at later stages in breeding. Analysis of variations in the transcriptome of developing grains of wheat of varying quality revealed a very highly differentially expressed gene, $w b m$, encoding a small cysteine rich protein (Furtado et al. 2015). The allele associated with high levels of expression was only found in genotypes that produced bread with a high loaf volume. The protein may play a key role in wheat quality and especially loaf volume by cross-linking the larger proteins in the gluten. Wheat quality had long been associated with the presence of large proteins (glutenins) that were used to explain dough elasticity and small proteins were not studied in attempts to explain loaf volume. Genomics provided for the first time a molecular explanation of the differences in loaf volume that had until that time required end product testing.

\section{Wheat milling yield}

The value of wheat to the flour miller is enhanced by the potential for a high yield of flour on milling leading to a search for traits that can be used to predict milling performance (Edwards et al. 2008, Edwards et al. 2010). Breeders of wheat need to ensure high flour yield as this will influence the value of the rain to the millers purchasing the grain. Selection for this trait is difficult as kilogram quantities are required for reliable estimation of milling performance and prevent early generation selection in breeding. Analysis of the transcriptome of the developing grain has revealed genes that are differentially expressed in genotypes that perform well and produce more flour on milling. Wheat genotypes with low expression of genes encoding fascilin-like arabinogalactan proteins produce more flour (Nirmal et al. 2017). The reduced expression of these cell adhesion proteins may allow the grain to break up more easily in the milling process and generate more flour. The potential for early generation selection for flour yield is a major contribution of genomics to wheat breeding.

\section{Traits that appear more complex}

Some quality traits may be more complex than those described above. However genomic analysis should be used to confirm this. Traits such as loaf volume and flour yield had been considered complex before the discovery of major genes controlling these traits. Traits worth such as malting performance in barley deserve investigation in this way. 


\section{RJ Henry}

\section{Genomes of cereal wild relatives expanding the gene pool for quality}

Genomics is characterizing the wider gene pool of cereal species (Henry and Nevo 2014) and uncovering novel alleles that could be utilised in enhancing the quality of cereal products. Analysis of the genomes of wild populations (Cronin et al. 2007, Brozynska et al. 2016) may provide understanding of how climate impacts (Fitzgerald et al. 2011) on grain composition and quality and may guide breeding for climate resilience in grain quality.

\section{Barley}

The relationship of barley with the progenitor gene pool (Zeng et al. 2018) is such that incorporation of novel traits from the wild is feasible. Barley for food and feed and barley for malting all have potential to benefit from the wider gene pool (Fox et al. 2003). Genomics tools have great potential to allow discovery of the genetic basis of quality and selection of varieties with improved quality using a wider gene pool.

\section{Rice}

The Oryza genus has many species with traits that may be useful in rice breeding (Stein et al. 2018, Tikapunya et al. 2017). Some wild species have starch properties that may have advantages in providing foods with slower digestibility in grains with desirable sensory attributes (Tikapunya et al. 2018). Wild resources provide options for changes in grain appearance, an import feature of rice as it is consumed as a whole grain. Grain size, shape and colour can be adjusted to consumer preferences (Tikapunya et al. 2018) and specifically the starch properties that may provide health advantages (Tikapunya et al. 2017).

\section{Sorghum}

The Sorghum genus (Dillon et al. 2007) has many species with novel traits that can be explored using genomics tools (Boyles et al. 2017). The wide gene pool across the genus has not yet been fully explored for novel grain attributes (Ananda et al. 2020). Improvements in protein and carbohydrate content for various end uses may be achieved by utilization of wild relatives.

\section{Wheat}

The wild wheat gene pool may prove a source of genes for producing high quality wheat with greater nutrient efficiency (e.g., nitrogen efficiency). The production of synthetic hexaploid wheat varieties from a wider range of progenitor species has already been successful in delivering agronomic advances and could be applied to advancing quality. Wheat quality may be substantially altered by future genetic innovations based upon genomic analysis (Henry 2007) and some to these changes could be based upon genes from wild relatives.

\section{New cereals}

A small number of cereal species contribute a large amount of global food. Food security would be enhanced by expanding the numbers of cereal species that contribute to human food supply. A great diversity of grass species are found worldwide and many of them may be candidates for domestication. Genomics can be used to identify the best targets and to support their rapid domestication by targeting the modification of known domestication genes (Malory et al. 2011) from other species. Research on Microlaena stipoides has shown the potential to produce a non-shattering variety for food production by mutagenesis of the shattering locus (Shapter et al. 2013). This has the potential to produce a temperate cereal that might find uses as a whole grain food similar to rice.

\section{Introducing novel variation to improve quality}

Variation that cannot be found in nature may be very useful for grain quality improvement. Traditional approaches in plant breeding have involved the use of mutagenesis. More recently genetic manipulation using recombinant DNA technology has allow the production of transgenic cereals. More recently the emergence of gene editing technology has provided a new platform for design of new cereal products (Henry 2019). This technology is also well suited to use in rapid domestication of wild grasses to produce new cereal crops. Many domestication events have involved mutations that result in loss of gene function and editing to knock out gene function is a very straightforward application of this technology. 


\section{FUTURE PROSPECTS}

Genomics provides tools for improvement of the nutritional and functional quality of current cereal species. It can also provide critical approaches to capture of diverse traits form wild relatives or even to the domestication of completely new cereal species. The analysis of wild and domesticated populations (Moner et al. 2020) suggest new traits might be captured from the wild gene pool. Modifications of the proportions of different tissues or cell types within the grain might support the nutritional enhancement of cereals (Gillies et al. 2012). Adaptation of cereal genomes to ensure nutritional and functional quality is retained in future climates (Shamloo et al. 2017, Sreenivasulu et al. 2015) will require extensive genomic understanding. Genomic tools are invaluable in understanding the impact of factors such as heat stress (Ragan et al. 2019) on gain quality and this will become essential in adapting to a changing climate.

\section{REFERENCES}

Ananda GKS, Myrans H, Norton SL, Gleadow R, Furtado A and Henry RJ (2020) Wild Sorghum as a promising resource for crop improvement. Frontiers in Plant Science 11: 1108.

Boyles RE, Pfeiffer BK, Cooper EA, Rauh BL, Zielinski KJ, Myers MT, Brenton Z, Rooney WL and Kresovich S (2017) Genetic dissection of sorghum grain quality traits using diverse and segregating populations. Theoretical and Applied Genetics 130: 697-716.

Bradbury L, Fitzgerald T, Henry R, Jin Q and Waters DLE (2005) The gene for fragrance in rice. Plant Biotechnology Journal 3: 363-370.

Bradbury L, Gillies S, Brushett D, Waters D and Henry R (2008) Inactivation of an aminoaldehyde dehydrogenase is responsible for fragrance in rice. Plant Molecular Biology 68: 439-449.

Brozynska M, Furtado A and Henry RJ (2016) Genomics of crop wild relatives: expanding the gene pool for crop improvement. Plant Biotechnology Journal 14: 1070-1085.

Cronin JK, Bundock PC, Henry RJ and Nevo E (2007) Adaptive climatic molecular evolution in wild barley at the isa defense locus. Proceedings of the National Academy of Sciences of the United States of America 104: 2773-2778.

Dillon S, Shapter F, Henry R, Cordeiro G, Izquierdo L and Lee LS (2007) Domestication to crop improvement: Genetic resources for Sorghum and Saccharum (Andropogoneae). Annals of Botany 100: 975-989.

Edwards M, Osborne B and Henry R (2008) Effect of endosperm starch granule size distribution on milling yield in hard wheat. Journal of Cereal Science 48: 180-192.

Edwards M, Osborne B and Henry R (2010) Puroindoline genotype, starch granule size distribution and milling quality of wheat. Journal of Cereal Science 52: 314-320.

Fitzgerald TL, Shapter FM, McDonald S, Waters DLE, Chivers IH, Drenth A, Nevo E and Henry RJ (2011) Genome diversity in wild grasses under environmental stress. Proceedings of the National Academy of Sciences of the United States of America 108: 21140-21145.

Fox GP, Panozzo JF, Li CD, Lance RCM, Inkerman PA and Henry RJ (2003) Molecular basis of barley quality. Australian Journal of Agricultural Research 54: 1081-1101.

Furtado A, Bundock PC, Banks PM, Fox G, Yin X and Henry RJ (2015) A novel highly differentially expressed gene in wheat endosperm associated with bread quality. Scientific Reports 5: 10446.

Gillies SA, Futardo A and Henry RJ (2012) Gene expression in the developing aleurone and starchy endosperm of wheat. Plant Biotechnology Journal 10: 668-679.

Henry R (2007) Genomics as a tool for cereal chemistry. Cereal Chemistry 84: 365-369.

Henry RJ (2012) Next-generation sequencing for understanding and accelerating crop domestication. Briefings in Functional Genomics 11: 51-56.

Henry RJ (2019) Genomics and gene-editing technologies accelerating grain product innovation. Cereal Foods World 64.

Henry RJ and Nevo E (2014) Exploring natural selection to guide breeding for agriculture. Plant Biotechnology Journal 12: 655-662.

Henry RJ, Furtado A and Rangan P (2018) Wheat seed transcriptome reveals genes controlling key traits for human preference and crop adaptation. Current Opinion in Plant Biology 45: 231-236.

Henry RJ, Rangan P and Furtado A (2016) Functional cereals for production in new and variable climates. Current Opinion in Plant Biology 30 : 11-18.

Jin Q, Waters D, Cordeiro G, Henry RJ and Reinke RF (2003) A single nucleotide polymorphism (SNP) marker linked to the fragrance gene in rice (Oryza sativa L.). Plant Science 165: 359-364.

Kumar A, Mantovani EE, Simsek S, Jain S, Elias EM and Mergoum M (2019) Genome wide genetic dissection of wheat quality and yield related traits and their relationship with grain shape and size traits in an elite x non-adapted bread wheat cross. Plos One 14: e0221826.

Malory S, Shapter FM, Elphinstone MS, Chivers IH and Henry RJ (2011) Characterizing homologues of crop domestication genes in poorly described wild relatives by high-throughput sequencing of whole genomes. Plant Biotechnology Journal 9: 1131-1140.

Moner AM, Furtado A and Henry RJ (2020) Two divergent chloroplast genome sequence clades captured in the domesticated rice gene pool may have significance for rice production. BMC Plant Biology 20: 472.

Murigneux V, Rai SK, Furtado A, Bruxner TJC, Tian W, Harliwong I, Wei H, Yang $B$, Ye Q, Anderson E, Mao Q, Drmanac R, Wang Ou, Peters BR, Xu M, Wu P, Topp B, Coin LJM and Henry RJ (2020) Comparison of 


\section{RJ Henry}

long-read methods for sequencing and assembly of a plant genome. GigaScience 9: giaa146.

Nirmal RC, Furtado A, Rangan P and Henry RJ (2017) Fasciclin-like arabinogalactan protein gene expression is associated with yield of flour in the milling of wheat. Scientific Reports 7: 12539.

Nirmal RC, Furtado A, Wrigley C and Henry RJ (2016) Influence of gene expression on hardness in wheat. PloS One 11: e0164746.

Rangan P, Furtado A and Henry R (2019) Differential response of wheat genotypes to heat stress during grain filling. Experimental Agriculture 55: 818-827.

Rangan P, Furtado A and Henry R (2020) Transcriptome profiling of wheat genotypes under heat stress during grain-filling. Journal of Cereal Science 91: 102895.

Rangan P, Furtado A and Henry RJ (2017) The transcriptome of the developing grain: a resource for understanding seed development and the molecular control of the functional and nutritional properties of wheat. BMC Genomics 18: 766.

Shamloo M, Babawale EA, Furtado A, Henry RJ, Eck PK and Jones PJH (2017) Effects of genotype and temperature on accumulation of plant secondary metabolites in Canadian and Australian wheat grown under controlled environments. Scientific Reports 7: 9133.

Shapter FM, Cross M, Ablett G, Malory S, Chivers IH, King GJ and Henry RJ (2013) High-throughput sequencing and mutagenesis to accelerate the domestication of Microlaena stipoides as a new food crop. PloS One 8: e82641.

Sreenivasulu N, Butardo VM, Misra G, Cuevas RP, Anacleto R and Kishor PBK (2015) Designing climate-resilient rice with ideal grain quality suited for high-temperature stress. Journal of Experimental Botany 66: 1737-1748.
Stein JC, Yu Y, Copetti D, Zwickl DJ, Zhang L, Zhang C, Chougule K, Gao D, Iwata A, Goicoechea JL, Wei S, Wang J, Liao Y, Wang M, Jacquemin J, Becker C, Kudrna D, Zhang J, Londono CEM, Song X, Lee S, Sanchez P, Zuccolo A, Ammiraju JSS, Talag J, Danowitz A, Rivera LF, Gschwend AR, Noutsos C, Wu C-M, Kao S-M, Zeng J-W, Wei F-J, Zhao Q, Feng $Q$, El Baidouri M, Carpentier M-C, Lasserre E, Cooke R, Farias DR, Maia LC, Santos RS, Nyberg KG, McNally KL, Mauleon R, Alexandrov $\mathrm{N}$, Schmutz J, Flowers D, Fan C, Weigel D, Jena KK, Wicker T, Chen M, Han B, Henry R, Hsing YC, Kurata N, Oliveira AC, Panaud O, Jackson SA, Machado CA, Sanderson MJ, Long M, Ware D and Wing RA (2018) Genomes of 13 domesticated and wild rice relatives highlight genetic conservation, turnover and innovation across the genus Oryza. Nature Genetics 50: 285-296.

Tikapunya T, Henry RJ and Smyth H (2018) Evaluating the sensory properties of unpolished Australian wild rice. Food Research International 103: 406-414.

Tikapunya T, Zou W, Yu W, Powell PO, Fox GP, Furtado A, Henry RJ and Gilbert RG (2017) Molecular structures and properties of starches of Australian wild rice. Carbohyd Polym 172: 213-222.

Wambugu P, Ndjiondjop MN, Furtado A and Henry R (2018) Sequencing of bulks of segregants allows dissection of genetic control of amylose content in rice. Plant Biotechnology Journal 16: 100-110.

Waters D, Henry R, Reinke R and Fitzgerald MA (2006) Gelatinization temperature of rice explained by polymorphisms in starch synthase. Plant Biotechnology Journal 4: 115-122.

Zeng X, Guo Y, Xu Q, Mascher M, Guo G, Li S, Mao L, Liu Q, Xia Z, Zhou J, Yuan H, Tai S, Wang Y, Wei Z, Song L, Zha S, Li S, Tang Y, Bai L, Zhuang Z, He W, Zhao S, Fang X, Gao Q, Yin Ye, Wang J, Yang H, Zhang J, Henry RJ, Stein N and Tashi N (2018) Origin and evolution of qingke barley in Tibet. Nature Communications 9: 5433. 